\title{
PERMAINAN KUDA BISIK UNTUK MENINGKATKAN KEMAMPUAN PEMBENDAHARAAN KOSAKATA ANAK USIA 5-6 TAHUN
}

\author{
Baiq Shofa Ilhami ${ }^{1}$, Baiq Febri Hijriatul Fitri ${ }^{2}$, Sandy Ramdhani ${ }^{3}$ \\ ${ }^{1,2,3}$ Universitas Hamzanwadi
}

\begin{abstract}
This research aims to describe the development of Kuda Bisik traditional game to improve the vocabulary of children in group B. The Research and developmet method was used in this study with type of Borg \& Gall which has been simplified into 3 main stages namely; needs analysis; product design; and product trials. Test subjects using 10 children in limited trials and 22 children from 2 schools of Ummi Adniyah Pancor Kindergarten and Hamzanwadi Pancor Kindergarten. Data collection techniques used were observation; tests and documentation with observation sheets as the instrument; product validation sheet; and test. The analysis technique uses the percentage of test results of learning outcomes with a classical success rate of 75\%. The results of his research are in the initial trials of the product in the form of a Kuda Bisik media game was well implemented. While the result of initial field of the 22 samples used from the two schools described that the vocabulary of children, is began to develop as expected (BSH) by 7 people or with a percentage of $32 \%$ and 15 children or $62 \%$ is very well developed (BSB), and learning outcomes tests found 8 children or 36\% developed as expected, and 14 children or $64 \%$ of children developed. It can be concluded that the Kuda Bisik product was able to improve the vocabulary children age 5-6 years old.
\end{abstract}

Keyword: child vocabulary, kuda bisik, traditional games

\begin{abstract}
Abstrak: Penelitian ini bertujuan untuk melihat hasil pengembangan permainan kuda bisik terhadap peningkatan kemampuan pembendaharaan kata anak usia 5-6 tahun. jenis pengembangan yang digunakan mengadapatasi tipe Borg \& Gall yang sudah disederhanakan menjadi 3 tahapan utama yaitu; analisis kebutuhan; desain produk; dan ujicoba produk. Subyek ujicoba dengan menggunakan 10 anak pada ujicoba terbatas dan 22 anak dari 2 sekolah yaitu TK Ummi Adniyah Pancor dan TK Hamzanwadi Pancor. Teknik pengumpulan data yang digunakan adalah observasi; tes dan dokumentasi dengan instrumen yang digunakan lembar observasi; lembar validasi produk; dan tes. Teknik analisis menggunakan hasil persentase tes hasil belajar dengan tingkat keberhasilan klasikal $75 \%$. Hasil penelitiannya adalah pada ujicoba awal produk berupa media permainan kuda bisik terlaksana dengan baik. Sedangkan hasil uji lapangan dari 22 sampel yang digunakan dari dua sekolah peningkatan pembendaharaan kosakata anak yaitu mulai berkembang sesuai harapan (BSH) sebanyak 7 orang atau dengan persentase $32 \%$ dan 15 anak atau $62 \%$ adalah berkembang sangat baik (BSB), dan tes hasil belajar didapatkan 8 anak atau 36\% berkembang sesuai harapan, dan 14 anak atau 64\% anak berkembang sangat baik. Sehingga dapat disimpulkan bahwa produk permainan kuda bisik mampu meningkatkan kemampuan pembendaharaan kosakata anak usia 5-6 tahun.
\end{abstract}

Kata Kunci: Kosakata anak, Kuda bisik, Permainan tradisional.

\footnotetext{
'Universitas Hamzanwadi, Email: shofa.ilhami国gmail.cam

${ }^{2}$ Universitas Hamzanwadi, Email: baiqfebrihijiriatulflägmail.com

${ }^{3}$ Universitas Hamzanwadi, Email: sandyl60392国qmail.cam
} 


\section{PENDAHULUAN}

PAUD merupakan upaya pemberian stimulus oleh pendidik PAUD terhadap pembentukan karakter serta mengembangkan kecerdasan dan kecakapan hidup agar anak usia dini kelak menjadi sosok manusia yang bermanfaat bagi dirinya sendiri, orang lain, dan lingkungan sekitarnya (Anggraeni, Hartati, \& Nurani, 2019). Pada tahap ini orang tua harus benarbenar memperhatikan pendidikan bagi anaknya baik dalam memilih lembaga pendidikan bagi anak atau memilih untuk mendidik sendiri sang anak dirumah. Proses kegiatan belajar di PAUD hendaknya memperhatikan metode dan media yang digunakan. Karena sering kali media dan metode yang digunakan sangat berperan penting dalam menambah minat belajar bagi anak. Manusia dalam kehidupannya tidak bisa terlepas dari bahasa. Walstra, Wouters, \& Geurts (2005) menjelaskan melalui bahasa, manusia akan mudah berkomunikasi, bergaul dengan lingkungannya, sehingga bahasa mempunyai peranan sangat penting bagi kehidupan manusia terutama dari sejak dini. Menyuk \& Brisk, (2005) menyatakan bahasa merupakan alat untuk berfikir, mengekspresikan diri dan berkomunikasi. Karakteristik perkembangan bahasa pada kelompok B diantaranya, menyusun kalimat sederhana dalam steruktur lengkap (pokok kalimat-predikat-keterangan), terlibat dalam pemilihan dan memutuskan aktivitas yang akan dilakukan bersama temannya, perbendaharaan kata lebih kaya dan lengkap untuk melakukan komunikasi verbal (Aprinawatidkk, 2017). Berdasarkan penjelasan tersebut maka perkembangan bahasa pada PAUD adalah perubahan sistem lambang bunyi yang berpengaruh terhadap kemampuan berbicara anak usia dini yang dimana kemampuan berbicara berpengaruh terhadap penguasaan kosakata anak.
Perkembangan bahasa tersebut anak diharapkan dapat atau memiliki perbendaharaan kosakata benda yang baik. PAUD adalah masa yang sangat strategis untuk menyerap perbendaharaan kata karena pada masa ini anak sangat peka terhadap rangsangan yang diterima dari lingkungannya. Penguasaan perbendaharaan kosakata dapat dilakukan dengan aktivitas bermain untuk menimbulkan aspek kesenangan. Merangsang perkembangan penguasaan kosakata benda pada anak dalam proses pembelajaran di PAUD harus menggunakan berbagai metode pembelajaran yang sesuai dengan karakteristik anak.

Pada proses pembelajaran ada beberapa metode yang dapat digunakan oleh pendidik untuk mendukung keberhasilan proses pembelajaran. Penggunaan metode pembelajaran harus memperhatikan tahap perkembangan anak, penggunaan metode yang sesuai dan beragam dapat menumbuhkan minat dan antusias anak dalam mengikuti proses pembelajaran yang sedang berlangsung. Pembelajaran di PAUD memberikan peranan penting dalam mengembangkan penguasaan kosakata benda karena penguasaan kosakata merupakan dasar untuk mengikuti pelajaran disekolah jenjang berikutnya (Brodin \& Renblad, 2019). Usia PAUD adalah usia bermain maka dalam pengembangannya harus melalui permaianan yang aktif, kreatif, dan menyenangkan (Yudiwinata \& Handoyo, 2014). Maka dari itu pendidik harus memiliki berbagai stategi dalam proses pembelajaran dalam pengembangan penguasaan kosakata benda. Salah satu cara yang baik dalam proses pembelajaran yaitu melakukan inovasi dalam proses pembelajaran seperti penerapan permainan tradisional dalam proses kegiatan pembelajaran.

Yudiwinata \& Handoyo (2014) menjelaskan Penerapan permainan tradisional dalam proses pembelajaran 
akan menghidupkan kembali permainanpermainan tradisional yang telah punah tergerus oleh zaman yang serba modern dan menambah minat belajar anak yang terkadang jenuh dengan proses pembelajaran. permainan tradisional akan memudahkan anak memahami apa yang diberikan oleh pendidik (Agustina \& Hafidz, 2018). Untuk menerapkan permainan tradisional, pendidik harus memiliki keterampilan dan kreativitas untuk membuat inovasi baru dalam permainan tradisional. Permainan tradisional merupakan permainan yang dimainkan oleh anak-anak pada zaman dahulu sebelum mengenal teknologi seperti saat ini (Ilhami \& Khaironi , 2018). Permainan tradisional terdiri dari berbagai jenis permaian seperti gobak sodor, engklak, petak umpet, bakiak, gasing, dan kuda bisik. Permainan tradisional ini mampu menstimulus pertumbuhan dan perkembangan dikarenakan dapat merangkul keseluruhan anak baik pada anak yang memiliki intelegensi yang rendah maupun yang tinggi

\section{TINJAUAN PUSTAKA}

Yudiwinata \& Handoyo (2014), mendefinisikan permainan tradisional sebagai permainan yang telah diturunkan dari satu generasi ke generasi berikutnya dengan permainan tersebut mengandung nilai "baik", "positif", "bernilai", dan "diinginkan yang merupakan tradisi dari daerah tertentu. Selain itu Adi Sam (2010) menjelaskan bermain pada anak usia dini sebagai sebuah konsep pembelajaran yang menarik dan mampu untuk mengembangkan kemampuan anak dari berbagai aspek, baik aspek kognitif, motorik sensorik, literasi, seni, dan sosioemosional. Permainan tradisional merupakan suatu hal mempunyai sejarah di daerah atau budaya tertentu yang di dalamnya mempunyai nilai-nilai kemanusiaan dan tidak merupakan industrialisasi.
Menurut Gustian, Supriatna, \& Purnomo (2019) permainan tradisional lebih banyak memberikan kesempatan kepada anak untuk bermain secara berkelompok. Permainan tradisional yang sarat dengan nilai-nilai budaya mengandung unsur rasa senang dan hal ini akan membantu perkembangan anak ke arah lebih baik dikemudian hari. Permainan ini juga dapat membantu anak dalam menjalin hubungan sosial baik dengan teman sebayanya (peer group) maupun dengan teman yang usianya lebih muda atau lebih tua. Salah satu permainan yang digunakan adalah permainan kuda bisik.

Saputra \& Ekawati (2017), mendeskripsikan permainan kuda bisik sebagai permainan tradisional yang berasal dari Betawi yang mampu untuk meningkatkan kemampuan berbahasa anak. Prosedur permainan kuda bisik ini adalah umlah pemain kuda bisik paling sedikit tujuh orang dan harus ganjil karena satu orang akan menjadi wasit dan sisanya membentuk dua kelompok. Wasit menerima bisikan dari dua kelompok (Saputra \& Ekawati, 2017)

Penguasaan Kosakata merupakan kegiatan menguasai atau kemampuan memahami dan menggunakan kata-kata yang terdapat dalam suatu bahasa, baik bahasa lisan, maupun tulisan (Kurniawati, Arini, \& Suarjana, 2016). Kosakata atau perbendaharaan kata adalah semua kata yang terdapat dalam suatu Bahasa (Rahmawati, 2013).

Penguasaan kosakata dapat memengaruhi keterampilan berbahasa seseorang, begitu juga dengan kemampuan seseorang menggunakan dan mempelajari bahasa banyak dipengaruhi oleh kosakata yang dimilik (Brodin \& Renblad, 2019; Menyuk \& Brisk, 2005). Bahasa dapat berfungsi kepada seseorang apabila keterampilan berbahasa seseorang meningkat. Keterampilan berbahasa seseorang meningkat apabila kuantitas dan kualitas kosakatanya meningkat. Kurniawati, Arini dan 
Suarjana (2016) mendeskripsikan anak mempelajari dua jenis kosakata, yakni kosakata umum, dan kosa kata khusus. Kosakata umum terdiri atas kata yang dapat digunakan dalam berbagai situasi yang berbeda. Kosakata khusus terdiri atas kata dengan arti spesifik yang hanya dapat digunakan dalam situasi tertentu. Kosakata umum terdiri atas kata benda, kata kerja, kata sifat, kata keterangan, dan kata keterangan sedangkan kosakata khusus terdiri atas kata warna, kata jumlah dan kata waktu (Rahmawati, 2013).

\section{METODOLOGI PENELITIAN}

Jenis penelitian yang digunakan adalah penelitian pengembangan dengan menggunakan model pengembangan tipe Borg and Gall yang diadaptasi menjadi 7 tahapan yaitu: analisis kebutuhan; perencanaan; prototype produk; ujicoba terbatas; revisi ujicoba terbatas; ujicoba lapangan dan revisi ujicoba lapangan (Gal et.al, 2007). Subyek penelitian adalah kelompok B TK Hamzanwadi Pancor dan TK Ummi Adniyah Pancor. Teknik dan instrument pengumpulan data yang digunakan adalah Teknik observasi, tes hasil belajar dan dokumentasi, sedangkan instrument pengumpulan datanya adalah menggunakan lembar observasi dan tes. Teknik Analisis keberhasilan yang digunakan adalah analisis deskriptif kualitatif untuk hasil validasi expert judgement dan menggunakan analisis deskriptif statistic kuantitatif dengan menggunakan persentase keberhasilan hasil belajar dari produk yang digunakan.

\section{HASIL PENELITIAN DAN PEMBAHASAN \\ Hasil Penelitian}

Berdasarkan hasil analisis kebutuhan yang dilaksanakan sebagai acuan dalam permainan tradisional kuda bisik didapatkan penguasaan kosakata anak khususnya kata benda masih kurang, kurangnya pemanfaatan permainan yang ada disekitar anak dan pendidik hanya menggunakan mediamedia yang serba instan seperti, majalah, papan tulis dan pemberian tugas. Selain itu pendidik kurang memanfaatkan kemajuan teknologi untuk mengakses metode-metode yang lebih menarik sehingga minak anak dalam belajar meningkat.

Hasil analisis kebutuhan kemudian digunakan sebagai acuan dalam mengembangkan suatu metode atau permainan yang dapat mengatasi masalah yang ada pada proses pembelajaran tersebut maka dikembangkan sebuah permainan untuk meningkatkan kemampuan pembendaharaan kata anak kelompok B. produk yang dihasilkan adalah Media pembelajaran yang disesuaikan dengan permainan kuda bisik. Isi dari produk yang dikembangkan adalah Buku panduan permainan, media pembelajarannya, dan alat evaluasi pembelajaran. berdasarkan hasil validasi dari expert judgement yaitu ahli materi dan ahli media didapatkan hasil validasi baik dengan beberapa masukan yaitu : (1) Bentuk dari media gambar yang berbentuk persegi yang digunakan menjadi macam-macam geometri agar anak bisa langsung mengenal bentuk geometri; (2) Mengubah background gambar menjadi beberapa warna agar anak bisa mengenal warna-warna, dan dapat memudahkan anak mengingat gambar yang ada; (3) Membentuk kolomkolom pada papan agar memudahkan anak menempelkan gambar secara berurutan; (4) Memperjelas indikator keberhasilan pada rubrik penilaian untuk instrumen observasi; (5) Pada instrumen tes hasil belajar anak pada bagian lembar kegiatan 1 menggunakan gambar tanpa warna agar nanti anak yang akan mewarnai sehingga anak akan antusias; dan (6) Untuk kata bantu pada lembar kegiatan 1 harus sejajar dengan gambar yang akan dilengkapi sehingga anak lebih mudah memahami isinya. 
Sedangkan berdasarkan hasil ujicoba hasil yang didapatkan adalah Uji coba lapangan awal/ ujicoba terbatas melibatkan 10 anak pada kelompok B. Pada uji coba ini dilakukan permainan Kuda Bisik dalam proses pembelajaran yang dimana anak dibagi menjadi dua kelompok yang masing-masing kelompok berjumlah 5 orang anak, kemudian setelah itu anak akan berbaris berbanjar dan pendidik menjelaskan aturan main dan pendidik menyebutkan satu kata secara bersamaan kepada anak pertama yang ada di kelompok masingmasing. Setelah itu anak membisikkan kata tersebut kepada temannya secara bergantian dan anak terakhir akan mengambil satu gambar sesuai yang didengar dan dibisikkan lalu menempelkannya pada papan yang telah disiapkan. Sedangkan dalam tes hasil observasi dijabarkan dalam table 01 berikut ini tentang hasil observasi penggunaan produk permainan kuda bisik adalah sebagai berikut

Tabel. 4.1 Hasil Observasi Penggunaan Produk Permainan Kuda Berisik

\begin{tabular}{|c|l|c|c|}
\hline No & Kategori & $\begin{array}{l}\text { Jumlah } \\
\text { Anak }\end{array}$ & $\begin{array}{l}\text { Hasil } \\
\text { Persentase }\end{array}$ \\
\hline 1 & Belum Berkembang & 0 & $0 \%$ \\
\hline 2 & Mulai Berkembang & 0 & $0 \%$ \\
\hline 3 & $\begin{array}{l}\text { Berkembang Sesuai } \\
\text { Harapan }\end{array}$ & 7 & $32 \%$ \\
\hline 4 & $\begin{array}{l}\text { Berkembang Sangat } \\
\text { Baik }\end{array}$ & 15 & $68 \%$ \\
\hline Jumlah & 22 & $100 \%$ \\
\hline
\end{tabular}

Hasil ujicoba utama didapatkan dari 22 sampel yang digunakan dari dua sekolah dideskripsikan hasil observasi penggunaan produk permainan kuda bisik untuk meningkatkan pembendaharaan kosakata anak yaitu mulai berkembang sesuai harapan (BSH) sebanyak 7 orang atau dengan persentase $32 \%$ dan 15 anak atau $62 \%$ adalah berkembang sangat baik (BSB). sedangkan untuk tes hasil belajar anak usia 5-6 tahun deskripsikan pada table 02 sebagai berikut:
Table 4.2 Hasil Tes Hasil Belajar Penerapan Permainan Kuda Bisik terhadap Pembendaharaan Kata Benda Anak Usia 5-6 Tahun

\begin{tabular}{|l|l|c|c|}
\hline No & Kategori & $\begin{array}{l}\text { Jumlah } \\
\text { Anak }\end{array}$ & $\begin{array}{l}\text { Hasil } \\
\text { Persentase }\end{array}$ \\
\hline 1 & $\begin{array}{l}\text { Belum } \\
\text { Berkembang }\end{array}$ & 0 & $0 \%$ \\
\hline 2 & $\begin{array}{l}\text { Mulai } \\
\text { Berkembang }\end{array}$ & 0 & $0 \%$ \\
\hline 3 & $\begin{array}{l}\text { Berkembang } \\
\text { Sesuai } \\
\text { Harapan }\end{array}$ & 8 & $36 \%$ \\
\hline 4 & $\begin{array}{l}\text { Berkembang } \\
\text { Sangat Baik }\end{array}$ & 14 & $64 \%$ \\
\hline \multicolumn{2}{|l|}{ Jumlah } & 22 & $100 \%$ \\
\hline
\end{tabular}

Hasil tes hasil ujicoba 22 anak Untuk tes hasil belajar didapatkan 8 anak atau $36 \%$ berkembang sesuai harapan, dan 14 anak atau 64\% anak berkembang sangat baik. Sehingga dapat disimpulkan bahwa anak berkembang sesuai harapan dengan menggunakan produk permainan kuda anak secara klasikal diperoleh data yang menunjukkan bahwa "100\%" anak sudah mencapai perkembangan Berkembang Sesuai Harapan Pada indikator ketercapaian dalam penelitian ini mengacu pada tingkat ketuntasan hasil belajar batas ketuntasan secara klasikal dari hasil belajar anak yaitu $75-80 \%$ sehingga, dari tes hasil belajar yang diperoleh sudah melebihi batas ketuntasan secara klasikal maka dapat disimpulkan bahwa penelitian ini dikatakan berhasil dengan berkembang sesuai harapan dan secara klasikal dapat disimpulkan bahwa produk hasil pengembangan permainan tradisional kuda bisik berupa media permainan kuda bisik mampu untuk meningkatkan pembendaharaan kosakata anak kelompok B.

\section{Pembahasan}

Pada saat dilakukan uji coba produk, perlakuan pertama yang dilakukan yaitu mengamati bagaimana karakter anak, perkenalan dengan anak, berbicara tentang tema lingkunganku dengan sub tema lingkungan rumah, 
memberi motivasi dengan cara bernyanyi kemudian melatih pendengaran anak dengan melakukan permainan berbisik sesuai dengan tema. Setelah itu memperkenalkan anak apa saja gambar benda yang ada di ruang tamu dan menyebutkan huruf apa saja yang ada digambar tersebut, lalu anak menyebutkan secara bergiliran. Setelah melakukan permainan dan pengenalan huruf kemudian memperkenal media papan dan gambar yang berbentuk geometri yang berisi gambar-gambar kata benda yang ada di ruang tamu.

Setelah anak mengenal bendabenda yang ada di ruang tamu maka, selanjutnya anak diberi tahu tentang permainan Kuda Bisik dan aturan main yang harus diikuti dan dipatuhi, pendidik mengajak anak untuk bermain Kuda Bisik, Dalam permainan Kuda Bisik anak akan secara bergantian menempelkan gambar yang dibisikkan oleh temannya dan berkesempatan untuk membisikkan kata kepada temannya. Pada saat dilakukan permainan Kuda Bisik anak sangat antusias dan bersemangat dalam mengikuti permainan namun, ada beberapa anak yang harus dituntun atau diingatkan kembali aturan mainnya (Gustian dkk., 2019).

(Ilhami \& Khaironi, 2018) memaparkan penerapan permainan tradisional memberika stimulus dalam penerapan pembelajaran yang baik bagi anak. Pembelajaran yang menarik, membuat anak aktif dan inovatif serta menjadikan anak tidak bosan dalam proses pembelajaran sehingga membutuhkan permainan tradisional yang menarik tentunya. (Kurniawati dkk, 2016; Rahmawati, 2013; Widaningsih, Ananthia, 2017) Pembendaharaan kosakata anak usia dini tidak terlepas ingkan sebelum dilakukan tindakan. Peningkatan pemahaman terhadap materi yang dipelajari siswa tersebut dipengaruhi oleh adanya ketertarikan anak ketika belajar membaca dengan menggunakan kartu kata. Anak lebih mudah memahami dan mengenal huruf yang menyusun suatu kata karena media yang digunakan lebih menarik. Anak merasa tertarik dengan huruf yang dibuat pada kartu menggunakan tulisan warna- warni sehingga anak lebih mudah mengingat bunyi huruf yang menyusun kata tersebut. Hal ini dibuktikan ketika guru menanyakan kembali susunan kata kepada anak, anak langsung membunyikan kata tersebut sesuai dengan tulisannya, serta menyebutkan huruf dan suku kata yang membentuknya.

Permainan tradisional ini juga dapat menumbuhkan nilai-nilai karakter pada anak, seperti nilai religius, nasionalis, mandiri, gotong royong, integritas. Karakter religious dikembangkan melalui kemampuan percaya diri dalam bermain, bersahabat, melindungi sesama teman, dan mencintai lingkungan (Saputra \& Ekawati, 2017). Karakter nasionalis dikembangkan melalui kemampuan menjaga lingkungan, taat aturan bermain, menjaga kekayaan bangsa, dan menghormati keragaman budaya, suku dan agama ketika bermain dengan teman sebaya lainnya.

(Heath et al., 2014; Nurani, 2017; Saputra \& Ekawati, 2017) Bermain adalah serangkain kegiatan atau aktivitas anak untuk bersenangsenang. Apapun kegiatannya, selama itu terdapat unsur kesenangan atau kebahagiaan bagi anak usia dini, maka dapat disebut sebagai bermain bermain adalah suatu kegiatan yang dilakuakan berulang-ulang dan menimbulkan kesenangan kepuasan bagi seseorang. Kemampuan berbahasa merupakan hasil kombinasi seluruh sistem perkembangan anak, karena kemampuan bahasa sensitif terhadap keterlambatan atau kerusakan pada sistem yang lain. Dalam hal ini, kemampuan berbahasa melibatkan motorik, emosional, sosial, dan kognitif. 
Dengan demikian, perkembangan bahasa adalah kemampuan untuk menangkap maksud yang ingin dikomunikasikan dan kemampuan berkomunikasi dengan orang lain, sehingga dapat dimengerti.

\section{KESIMPULAN}

Hasil ujicoba utama didapatkan dari 22 sampel yang digunakan dari dua sekolah dideskripsikan hasil observasi penggunaan produk permainan kuda bisik untuk meningkatkan pembendaharaan kosakata anak yaitu mulai berkembang sesuai harapan (BSH) sebanyak 7 orang atau dengan persentase $32 \%$ dan 15 anak atau $62 \%$ adalah berkembang sangat baik (BSB). Hasil tes hasil ujicoba 22 anak Untuk tes hasil belajar didapatkan 8 anak atau 36\% berkembang sesuai harapan, dan 14 anak atau $64 \%$ anak berkembang sangat baik. Sehingga dapat disimpulkan bahwa anak berkembang sesuai harapan dengan menggunakan produk permainan kuda anak secara klasikal diperoleh data yang menunjukkan bahwa "100\%" anak sudah mencapai perkembangan Berkembang Sesuai Harapan Pada indikator ketercapaian dalam penelitian ini mengacu pada tingkat ketuntasan hasil belajar batas ketuntasan secara klasikal dari hasil belajar anak yaitu $75-80 \%$ sehingga, dari tes hasil belajar yang diperoleh sudah melebihi batas ketuntasan secara klasikal sehingga produk pengembangan permainan kuda bisik berupa media permainan dan evaluasi mampu untuk meningkatkan kemampuan pembendaharaan kosakata benda anak usia 5-6 tahun.

\section{DAFTAR PUSTAKA}

Adi Sam, T. T. (2010). Permainan Anak Yang Menggunakan Nyanyian (Kajian Wilayah: Jakarta, Depok, Bogor, Tangerang, dan Bekasi). Harmonia Journal of Arts Research and Education, 10(2). https://doi.org/10.15294/harmonia.v
$10 \mathrm{i} 2.57$

Anggraeni, D., Hartati, S., \& Nurani, Y. (2019). Jurnal Obsesi : Jurnal Pendidikan Anak Usia Dini Implementasi Metode Bercerita dan Harga Diri dalam Meningkatkan Kemampuan Berbicara Anak Usia Dini, 3(2), 404-415. https://doi.org/10.31004/obsesi.v3i2. 224

Aprinawati, I., Pendidikan, P., Sekolah, G., Fakultas, D., Pendidikan, I., Pahlawan, U., \& Tambusai, T. (2017). Jurnal Obsesi : Jurnal Pendidikan Anak Usia Dini Penggunaan Media Gambar Seri Untuk Meningkatkan Kemampuan Berbicara Anak Usia Dini, 1(1), 1218.

https://doi.org/10.31004/obsesi.v1i1. 33

Gall, M. D., Gall, J. P., \& Borg, W. R. (2007). Educational research: an introduction (8. utg.).

Brodin, J., \& Renblad, K. (2019). Improvement of preschool children's speech and language skills. Early Child Development and Care, $\quad 0(0), \quad 1-9$. https://doi.org/10.1080/03004430.20 18.1564917

Gustian, U., Supriatna, E., \& Purnomo, E. (2019). Efektifitas modifikasi permainan tradisional dalam pengembangan physical literacy anak taman kanak-kanak. Jurnal Keolahragaan, 7(1), 23-33.

Heath, S. M., Bishop, D. V. M., Bloor, K. E., Boyle, G. L., Fletcher, J., Hogben, J. H., ... Yeong, S. H. M. (2014). A spotlight on preschool: The influence of family factors on children's early literacy skills. PLoS ONE, 9(4). https://doi.org/10.1371/journal.pone. 0095255

Agustina, Y., \& Hafidz, I. P. (2017). 
Optimalisasi Media Permainan Kartu Abaca Untuk Meningkatkan Kemampuan Membaca Dini Pada Kelompok B TK Al-Hasaniyah NW Jenggik. Jurnal Golden Age, 1(02)..

Kurniawati, C. H., Arini, N. W., \& Suarjana, M. (2016). Penerapan Model Pembelajaran Inside Outside Circle Untuk Meningkatkan Keterampilan Berbicara.

Menyuk, P., \& Brisk, M. E. (2005). Language development and education: Children with varying language experiences. Language Development and Education: Children With Varying Language Experiences, 1-220. https://doi.org/10.1057/9780230504 325

Nurani, Y. (2017). Pengembangan Model Kegiatan Sentra Bermain Dalam Mengembangkan Kreativitas Anak Usia Dini. JPUD - Jurnal Pendidikan Usia Dini, 11(2), 386400.

https://doi.org/10.21009/jpud.112.15

Ramdhani, S., Yuliastri, N. A., Sari, S. D., \& Hasriah, S. (2019). Penanaman Nilai-Nilai Karakter melalui Kegiatan Storytelling dengan Menggunakan Cerita Rakyat Sasak pada Anak Usia Dini. Jurnal Obsesi: Jurnal Pendidikan Anak Usia Dini, 3(1), 153-160.

Rahmawati, N. (2013). Pengaruh Media Pop-Up Book Terhadap Penguasaan Kosakata Anak Usia 5-6 Tahun Di Tk Putera Harapan Surabaya. PAUD Teratai, 3(1), 5-6.

Saputra, N. E., \& Ekawati, Y. N. (2017). Meningkatkan Kemampuan Dasar Anak Tradisional Games in Improving Children ' S Basic Abilities. Jurnal Psikologi Jambi, 2(2), 48-53.

Ilhami, B. S., \& Khaironi, M. (2018). Pelaksanaan Joyfull Learning
Berbasis Permainan Tradisional Sasak Untuk Meningkatkan Motorik Kasar Anak Usia 5-6 Tahun. Jurnal Golden Age, 2(2), 59-65.

Walstra, P., Wouters, J. T. M., \& Geurts, T. J. (2005). Second Edition Second Edition. Dairy Science \& Technology, CRC Taylor \& Francis Group, 441-445.

Widaningsih, E., Ananthia, W., \& Bercerita, M. G. (n.d.). MEDIA GAMBAR BERCERITA UNTUK USIA DINI.

Yudiwinata, H. P., \& Handoyo, P. (2014). Permainan Tradisional dalam Budaya dan Perkembangan Anak. Paradigma, 02, 1-5. 